\title{
La lengua, «pluma de scriviente ábil»: el Salterio traducido por Juan de Valdés del hebreo*
}

\author{
Lola Pons Rodríguez** \\ Universidad de Sevilla \\ ORCID ID: https://orcid.org/0000-0002-3747-1354
}

Saca mi coraçón cosa buena; dedico yo mis obras al rey. Mi lengua pluma de screuiente ábil en escrivir (Salmo 45,1-2, traducción valdesiana)

Obra tardía dentro de su producción, la traducción que Juan de Valdés hizo desde el hebreo de los Salmos incluye datos de notable relevancia para aumentar nuestro conocimiento sobre el uso que prescribía y que escribía este autor. En este trabajo nos ocuparemos de ello y estudiaremos la información que sobre el hecho de traducir da Valdés en las páginas introductorias de la obra, dedicada a Julia Gonzaga. Igualmente, ubicaremos el lugar que ocupa esta traducción dentro de la propia empresa traductológica de Valdés, que ya había traducido desde el griego algunas partes del Nuevo Testamento y algunas epístolas de san Pablo. Por último, se contrastará particularmente el uso lingüístico prescrito y descrito por Valdés en el Diálogo de la lengua y el utilizado por el mismo autor al traducir los Salmos.

Palabras clave: Biblia; traducción; Diálogo de la lengua; Salmos; Historia de la lengua española.

The Language as the Pen of a Good Scrivener: The Hebrew Psalterium Translated into Spanish by Juan de Valdés.- This article deals with Juan de Valdés' translation of the Psalms from the Hebrew; his work includes relevant data about the distance between what he prescribed and what he actually wrote. We study the information Valdés gives about translating in the introductory pages of the work, dedicated to Julia Gonzaga. We describe the position of this translation in the Valdesian biblical production, as he translated from the Greek some parts of the New Testament and several Saint Paul's epistles.

Keywords: Bible; Translation; Diálogo de la lengua; Psalms; History of the Spanish Language.

* Este trabajo se desarrolla dentro del proyecto FFI2016-74828-P La Escritura Elaborada en Español de la Baja Edad Media al Siglo XVI: Traducción y Contacto de Lenguas (Historia15).

**1olapons@us.es

Copyright: (C) 2021 CSIC. Este es un artículo de acceso abierto distribuido bajo los términos de la licencia de uso y distribución Creative Commons Reconocimiento 4.0 Internacional (CC BY 4.0). 


\section{Prefacio}

El libro bíblico de los Salmos ${ }^{1}$ tiene en el occidente europeo medieval un uso constante y dilatadísimo como fuente libresca que acompaña, inspira y empuja el cultivo intelectual. Si Berceo decía de san Millán de la Cogolla que fue en poco de tiempo el pastor psalteriado / de imnos e de cánticos sobra bien decorado (Vida de San Millán de la Cogolla, 21) es porque la formación de los jóvenes monjes incluía como paso fundamental en su proceso de iniciación el saber leer bien los Salmos, e incluso, directamente, el aprender a leer latín a través de ellos. Como colección de salmos, los salterios eran libros que podían ser atesorados por laicos; estos - llamados salterios bíblicos por contraste con los $l i-$ túrgicos o usados en la celebración eucarística - también pudieron usarse para fines no primariamente religiosos como el de aprender latín, de ahí que se señale a los salmos como «primer texto de la Biblia aprendido de memoria por los clerici y texto que podía ser estudiado por las mujeres» ${ }^{2}$.

1 Para un estado de la cuestión de la historia textual de los Salmos como libro bíblico hasta los años 70, vid. Jan Kornelis Holman, «El estudio del Salterio de 1955 a 1970», Scripta Theologica 2:1 (1970) págs. 175-194.

2 Vid. Pilar Lorenzo Gradín, «La Biblia en la épica medieval», en La Biblia en la literatura española. I. Edad Media. El imaginario y sus géneros, dir., Gregorio Del Olmo

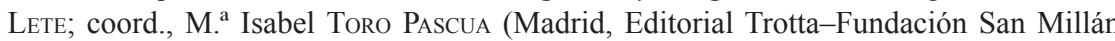
de la Cogolla, 2008) págs. 221-236: 224. Son numerosas las citas que acreditan que los Salmos, transmitidos como salterios, eran de circulación común entre los alfabetizados medievales; valgan como muestra dos de ellas extraídas del Corbacho (1438) de Martínez de Toledo: «Todas estas cosas fallaréys en los cofres de las mugeres. Oras de Santa María, syete salmos, estorias de santos, Salterio en rromançe ¡nin verle del ojo!, pero cançiones, dezires, coplas, cartas de enamorados e muchas otras locuras, esto sý». Como señala Avenoza: «hay que tener en cuenta [...] que el cristiano no está obligado a leer la Biblia, sino todo lo contrario. Se leían como mucho las partes incorporadas a la liturgia y vinculadas al ejercicio de la piedad (los salmos y más concretamente los salmos penitenciales, los pasajes neotestamentarios incluidos en las meditaciones sobre la Pasión y los fragmentos de diversa índole insertos en los libros de horas)». Vid. Gemma AvenozA, «Las traducciones de la Biblia en castellano en la Edad Media y sus comentarios», en La Biblia en la literatura española. I. Edad Media. I/2. El texto: fuente y autoridad, dir. G. DEL Olmo, y coord. M. ${ }^{\text {a }}$ I. Toro (Madrid: Editorial Trotta-Fundación San Millán de la Cogolla, 2008) págs. 13-75: 14. 
Entre autores conversos, tanto en Castilla como en otros entornos de Europa central, se inicia en el XV y se desarrolla y asienta después un movimiento que valora los salmos como texto cuyo uso debería trascender al del mero cultivo oracional que se había hecho rutinario en la Plena Edad Media. Se despierta en esa horquilla del Cuatrocientos al Quinientos un gran interés por el significado de este libro de la Biblia como herramienta para la oración individual y se acrecientan las versiones poéticas y traslaciones de la obra al romance. En el contexto quinientista, se siguen atesorando y evocando los Salmos como una constante de la cultura y la práctica religiosa, pero con nuevas perspectivas y materiales que se proponen renovar la trascendencia de este libro dentro de la práctica devota particular. En ese momento hay que situar la traducción que en Nápoles hizo el humanista conquense Juan de Valdés. En este trabajo presento dicha traducción dentro de su ambiente histórico y en el contexto de la propia producción valdesiana y de sus preferencias lingüísticas. Me ocupo, en primer lugar, (§ 2) de presentar las traducciones al romance castellano que se conocen de los Salmos en el xv y en el XVI y de contextualizar a Valdés como traductor bíblico (\$ 2.2). En $\S 3$ ofrezco los datos básicos que caracterizan el Salterio valdesiano: fecha, fuente, paratexto, testimonio en que circula, así como las decisiones traductológicas que de forma explícita asume al emprender el trabajo de traducción, expresadas en su introducción y su comento. Por último, (en $\S 4)$ me acerco a la lengua de la obra, sobre todo por contraste con algunas valoraciones presentes en el Diálogo de la lengua.

\section{VALDÉS COMO TRADUCTOR BÍBLICO}

\subsection{El Salterio valdesiano en la tradición de los Salmos traducidos}

La obra de Valdés se incluye en la larga y antigua lista de salterios traducidos al castellano, inaugurada en la Edad Media con la versión romance del Salterio de Hermann el Alemán, la más antigua de las versiones bíblicas castellanas. ${ }^{3}$ Tras ella, se conocen varias traducciones de

3 Vid. M. ${ }^{a}$ Wenceslada de Diego Lobejón, El Salterio de Hermann el Alemán. Ms. Escurialense I.i.8. (Valladolid: Universidad de Valladolid, 1993). 
los Salmos al castellano. Dejando a un lado las versiones poéticas, las evocaciones más o menos específicas o las parodias, y tratando solo de traducciones en prosa, tenemos constancia de más de una decena de versiones romances medievales; en ellas, es relevante atender a la lengua de la traducción, ya que fue común que en cuerpos bíblicos completos el Salterio ofreciese un cambio de fuente, lo que fue explicado por Avenoza ${ }^{4}$ por razones de «relevancia litúrgica». Además de traducciones romances (donde habría que incluir también las traducciones de los Salmos al catalán, desde el hebreo y desde el latín) no impidió que se siguieran copiando versiones latinas o hebreas de esta obra.

En el XVI, además de la traducción valdesiana, que solo se conoció en forma manuscrita, contamos con, al menos, otras dos traducciones individualizadas del Salterio en prosa: El Psalterio de David traduzido en lengua castellana, impreso en Lyon (1550) por Sébastien Gryphius, así como la famosa versión de Juan Pérez de Pineda ${ }^{5}$. A ellas hay que sumar el libro de Salmos traducido en la Biblia de Ferrara y en la conocida como Biblia del Oso. En el XVII tenemos conocimiento de nuevas versiones como la de Juan de Enzinas (Los Psalmos de Dauid metrificados en lengua castellana por Iuan le Quesne conforme a la traducion verdadera del texto hebreo, 1606) ${ }^{6}$, que a diferencia de los Salmos que puso en circulación Valdés o los de Juan Pérez, tenían una

${ }^{4}$ Gemma Avenoza, «Traducciones, público y mecenazgo en Castilla (siglo XV)», Romania 128 (2010) págs. 452-500: 460.

5 Los Psalmos de Dauid: con sus sumarios en que se declara con breuedad lo contenido en cada Psalmo agora nueua y fielmente traduzidos en romançe castellano por el doctor Iuan Perez, conforme ala verdad dela lengua Sancta versión de Juan Pérez de Pineda, impresa en Venecia (pie de imprenta falso por Ginebra) en 1557 por Pedro Daniel (pie de imprenta falso: Jean Crespin). La obra fue tenida por valdesiana por Usoz, que en una de sus cartas a Benjamin Wiffen se basa en el libro de Thomas M'Crie, History of the Progress and Suppression of the Reformation in Spain in the Sixteenth Century (Edinburgh: William Blackwood-London: T. Cadell, 1829) sobre protestantismo para dar esa referencia errónea, vid. Juan B. VILAR y Mar VILAR, El primer hispanismo británico en la formación y contenidos de la más importante biblioteca de libros prohibidos (Sevilla: Cimpe-Mad Eduforma, 2010) págs. 156 y 159.

6 José C. NiETo (El Renacimiento y la otra España: visión cultural socioespiritual [Génève: Droz, 1997]) le dedica unas esclarecedoras páginas. La obra se puede consultar en los fondos de la Biblioteca Digital Hispánica de la BNE y hay una edición moderna de ella. 
intención poética más que propiamente parenética, y otra posterior, sin atribución de autoría (Los Psalmos de Dauid: dirigidos en forma de oraciones, 1628).

La prohibición del vernáculo para las Biblias, como vemos, afectó irregularmente a los Salmos: el Índice expurgatorio (1551) prohíbe las versiones completas de la Biblia sin detallar nada acerca de las versiones parciales, el de Fernando Valdés (1559) prohíbe específicamente la traducción del Salterio, Job, Proverbios y el Nuevo Testamento, aunque también, de forma genérica «Todos y quealesquier sermones, cartas, tractados, oraciones o otra cualquier escriptura scripta de mano, que hable o tracte de la Sagrada Escriptura». En ese índice de 1559 se prohíben salterios que circulaban traducidos (el de Pérez de Pineda, el de Raynero, de Rainer Snoy de Gouda o las Lamentaciones romanceadas de Hernando de Jaraba); no se incluyó el de Valdés porque, al haberse escrito en Nápoles y circular manuscrito, quedaba fuera del conocimiento directo del inquisidor.

Los Salmos, por tanto, continúan siendo en los albores de la Edad Moderna un texto tan leído como en la Edad Media, pero distan de ser esa obra inserta en la ortodoxia y la rutina más común heredada tradicionalmente: el propósito de leer los Salmos para entenderlos y de acuerdo a una idea de estudiar y examinar la palabra bíblica se da durante el Quinientos como peldaño para una renovación y reforma de la fe, por eso, en el XVI se reúnen tendencias que se acercan con nuevos ojos a esta obra bíblica.

Por un lado, se promueven versiones fidedignas y renovadas del texto. En el rezo esclerotizado de los Salmos, igual que en prácticas externas como la adoración a los santos y la gestión de bulas y privilegios, se simbolizan para muchos de los revisionistas del XVI los procedimientos más vacuos de la religiosidad de su tiempo. De hecho, son los Salmos la alusión más inmediata que pone en boca de sus personajes Alfonso de Valdés cuando ataca en sus dos Diálogos el rezo inmotivado que era común en su tiempo ${ }^{7}$. En los círculos ortodoxos y heterodoxos

${ }^{7}$ El personaje de Latancio afirma en el Diálogo de las cosas acaecidas en Roma: «piensan otros porque rezan un montón de salmos o manadas de rosarios, otros porque traen un hábito de la Merced, otros porque no comen carne los miércoles, otros porque se visten de azul o naranjado, que ya no les falta nada para ser muy buenos cristianos» (pág. 217); por su parte, en el Diálogo de Mercurio y Carón (pág. 104) el personaje de Mercurio recrimina a otro: «no sé si se puede llamar oración el ensartar salmos como lo 
del XVI el Salterio es un libro muy presente. Unos lo siguen recibiendo por la tradición heredada, con sus encorsetamientos; otros buscan en el Salterio una respuesta a preguntas concretas de $\mathrm{fe}^{8}$. Esa nueva corriente que mira a los salterios tiene además otra nota adicional que la hace sospechosa pero que, sin duda, ayuda a entender el auge del estudio y lectura de los Salmos en el Quinientos. El Salterio va a aparecer en numerosos procesos inquisitoriales, por haber sido traducido o usado por judeoconversos. Los Salmos fueron la «fuente principal de oración de las comunidades hebreas» ${ }^{9}$, sea en forma de traducción directa o en los libros sustitutorios que se recogen en los procesos inquisitoriales por criptojudaísmo ${ }^{10}$; de hecho, como afirma Gitlitz ${ }^{11}$, era común la aprehensión por parte de la comunidad judía de «por muy católico que fuera, prácticamente todo libro en que hubiera un salmo».

Añadamos a esto una corriente que afecta a los Salmos, heredada de la Edad Media, y que se explota con mayor fruición aún en el xvI: su recreación lírica. Los Salmos contaban con un importante cultivo poético dentro del inmenso corpus cancioneril y en el XVI continuaron las recreaciones poéticas y traducciones en prosa de todos los Salmos, una parte de ellos (gran éxito tuvieron los penitenciales) o uno en concreto. Odas y églogas se convirtieron en esa centuria en el soporte métrico para que los Salmos

hazéis». Vid. Alfonso de VAldés, Diálogo de las cosas acaecidas en Roma, ed. Rosa Navarro Durán (Madrid: Cátedra, 1992), y Diálogo de Mercurio y Carón, ed. Joseph Ricapito (Madrid: Castalia, 1993).

8 Michel Boeglin, «Salterios y comentarios al Salmo en el Quinientos en Castilla: entre herencia conversa y sensibilidad evangélica: el Beatus Vir (1546) del doctor Constantino», Cahiers d'Études des cultures ibériques et latino-américaines 3 (2017) págs. 59-73.

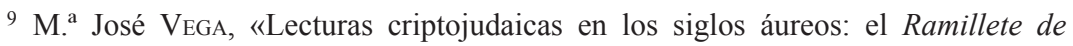
flores», Studia Aurea 4 (2010) págs. 37-51: 46.

${ }^{10}$ Cuando los índices tridentinos reducen las posibilidades de que circulen traducciones al vernáculo de los Salmos, las llamadas lecturas sustitutorias que comenzaron a pulular para reemplazarlo solían ser trataditos donde se explicaban conceptos bíblicos sin que faltase en ellos la exposición de un salmo o varios en concreto. La bibliografía sobre ellos puede verse en VEGA, «Lecturas criptojudaicas en los siglos áureos», que estudia el Ramillete de flores de todos los psalmos y cánticos de Pedro Ruiz de la Visitación (Palma de Mallorca, 1588), como libro que no versiona sino que describe los Salmos y que fue de amplia circulación en comunidades hebreas.

11 David Giturtz, Secreto y engaño. La religión de los criptojudios (Salamanca: Junta de Castilla y León, 1997 [2003]) pág. 379. 
y el Cantar de los cantares, respectivamente, conformasen una especie de sistema poético bíblico. Por otra parte, la poesía neolatina del Quinientos conoce un relevante número de versiones metrificadas del Salterio inspiradas en la métrica horaciana, que suponen al utilizar el esquema de la oda una innovación con respecto a otras versiones medievales latinas en metro que usaban el dístico elegíaco y que prolongan su difusión en la primera treintenta del siglo XVI ${ }^{12}$. Aunque el salmo se va a identificar con la forma clásica y cristianizada de la oda, e incluso se hagan equivalentes indistintamente ambos vocablos ${ }^{13}$, esta filiación entre poesía clásica y bíblica consumada en el XVI contaba con los precedentes de los judíos alejandrinos, lo que, de nuevo, explica que en la época postridentina los Salmos versionados poéticamente también encontrasen cercenada su libre circulación por la acción de la Inquisición (Núñez Rivera cifra en la etapa 1559 y los veinte años siguientes la fase de más estricta vigilancia) ${ }^{14}$. Pese a las prohibiciones, la escritura poética de inspiración davídica y tema religioso continuó durante el siglo XVII en toda Europa ${ }^{15}$.

\subsection{Evangelio, San Pablo y Salmos: las traducciones biblicas valdesianas}

A tenor de los testimonios conservados, hasta donde sabemos, Juan de Valdés fue el primer español del XVI que nos dejó traducciones cas-

12 Abarcan un conjunto de seis versiones desde 1531 a 1544.

13 Los paralelos entre oda horaciana y salmo bíblico se observaban no solo en el acompañamiento musical que ambas formas tuvieron en su origen, manifiesta primariamente en la etimología de ambas voces, sino en cuestiones formales (la estructura en cinco libros de los Salmos y los carmina horacianos) o temáticas (la oda se dirige al campeón, vencedor de la batalla, o a la reflexión sentenciosa).

14 Vid. Valentín NúÑez Rivera, «Los Salmos Penitenciales en la poesía de cancionero», en Poesía y Biblia en el Siglo de Oro. Estudios sobre los Salmos y el Cantar de los Cantares (Madrid: Universidad de Navarra-Iberoamericana-Vervuert, 2010) págs. 81-115: 81.

15 Para una revisión de la métrica empleada en las versiones poéticas del Salterio a partir del Quinientos, vid. Luis Alonso ScHÖKEL, «Traducciones rítmicas de Salmos», en "Mis fuentes están en ti". Estudios bíblicos de Literatura Española, eds. Luis Alonso SchÖKEl y Eduardo Zurro (Madrid: Universidad Pontificia de Comillas, 1998) págs. 243-287. 
tellanas de libros de la Biblia, y no solo fue el primer traductor, sino que, merced a los comentos del Salterio, fue también el primer comentarista bíblico en castellano de esa centuria ${ }^{16}$. En su primera obra y la única de su producción en pasar por los tórculos, el Diálogo de doctrina cristiana (1529, Alcalá de Henares, Imprenta de Eguía), Valdés incluyó al final la traducción desde el griego de los capítulos 5, 6 y 7 del Evangelio de San Mateo. Tras esa traducción, hecha en su etapa universitaria, tenemos traducciones y comentos bíblicos emprendidos durante su etapa italiana, cuando ya había abandonado para siempre España por temor de la represión inquisitorial y en la que sus escritos teológicos tratan de animar, formar y sostener espiritualmente al grupo que lo rodeaba en Nápoles. A esa etapa pertenecen la traducción del Salterio, los comentarios a la primera epístola de san Pablo a los corintios, los comentarios y la traducción de la epístola de san Pablo a los romanos y los comentarios al evangelio de san Mateo. Es posible que Valdés tradujera otros libros testamentarios además de Mateo y el Salterio, pero la traducción de los Salmos es la única traducción completa suya de un libro bíblico que conservamos.

Tanto el Salterio como el comentario de san Pablo a los Romanos fueron dedicados a Julia Gonzaga (1513-1556) la confidente y más destacada discípula de Valdés desde que entraron en contacto en 1536. Las menciones internas que hay en las dedicatorias de ambas obras nos permiten establecer entre ellas una cierta cronología interna. Así, en la introducción a los Salmos menciona el trabajo que está haciendo con las cartas paulinas (quizá aludiendo a la epístola a los corintios, que a la postre habría dedicado al emperador Maximiliano) (1) y en la introducción a la epístola a los romanos comenta a Julia Gonzaga cómo se

${ }^{16} \mathrm{Si}$ bien la prelación tiene el valor relativo de cualquier cuestión que utiliza un elemento tan convencional como el cambio de siglo para ser fijada, asumimos esa frase por lo que tiene de representativo el hecho de que de toda la escuela que pasa por una universidad como la de Alcalá, que había tenido en su centro a un proyecto traductológico de la envergadura de la Políglota complutense, Valdés será el primero que, por cronología, dé a la imprenta un fragmento bíblico traducido. Su prelación al ser el primer quinientista en traducir los Salmos al castellano habría de ser matizada si existió, como se ha supuesto, una traducción de los Salmos impresa en Sevilla en el año de 1500 y hecha por Hernando de Talavera, de la que hay alguna noticia indirecta (Philobiblon Beta, texid 4049). 
relaciona la traducción de los Salmos que ya le ha remitido con esta nueva obra (2):

(1) Hora, quiero que sepa Vuestra Señoria que lo que he hecho en los Salmos de Dauid, quise hazer primero en las Epistolas de san Pablo, entendiendo que, assy como la licion de Dauid, quando son bien considerados y bien entendidos sus diuinos concettos y sus espirituales sentimientos, sirue mucho para encaminar al hombre en la verdadera piedad, que es por el conocimiento a Dios, y para acrecentar al que es ya entrado en ella; assy tambien la licion de san Pablo, quando son bien considerados y bien entendidos sus diuinos concettos y sus espirituales sentimientos, sirue mucho para encaminar al hombre en la verdadera justificacion ${ }^{17}$.

(2) Persuadiendome Illustrissima Señora, que por medio de la continua lecion de los Psalmos de Dauid qu'el año passado os embie traduzidos del Hebreo en romance Castellano, aureys formado dentro de uos un animo tan pio, y tan confiado en Dios y remitido en todo a Dios, como era el de Dauid, y desseando que pasando mas adelante formeys dentro de vos vn animo tan perfeto, tan firme y assi constante en las cosas que pertenecen al Euangelio de Christo, como era el de san Paulo, os enbio agora estas Epistolas de san Paulo traduzidas del Griego en romance Castellano ${ }^{18}$.

Parece, pues, que las epístolas paulinas y el Salterio formaron parte de una suerte de programa formativo hacia la verdadera piedad dirigido por Valdés en que la traducción salmorial no es azarosa ni fruto de una libre elección, sino que emana de una responsabilidad tutorial de cara al círculo de devotos que Valdés lidera en Italia, visibilizado en la figura de la dedicataria Julia Gonzaga y a los que se dirigirían las cartas paulinas, los $\operatorname{Salmos}^{19}$ y el comento de san Mateo.

17 Manuel CArrasco, (ed.), Joya literaria. Comentario a los Salmos escrito por Juan de Valdés en el siglo XVI y ahora impreso por primera vez (Madrid: Librería Nacional y Extranjera, 1885) pág. 6.

18 Comentario o declaraciom breve, y compendiosa sobre la Epistola de S. Paulo Apostol (...) compvuesto por Ivan Valdesio (Venecia: Iuan Philadelpho, 1556) pág. 3.

19 Ambas obras parecen haber sido trabajadas por Valdés en paralelo, pues no faltan menciones a los Salmos en sus comentarios a las epístolas. 
Para explicar el evidente interés veterotestamentario que se observa en Valdés se ha aducido una posible inclinación hebrea explicada por sus orígenes conversos. Pero posiblemente, más que mirar al pasado valdesiano haya que hacerlo a su propio presente. Si Valdés escoge traducir los Salmos es porque participa de las corrientes revisionistas que en Europa occidental se acercan a tal libro. En Italia Valdés encuentra toda una corriente que prestigia a los salmos a través de su conversión poética en oda horaciana; Horacio es poeta muy querido por Valdés, que lo menciona varias veces en su Diálogo de la lengua y justamente uno de los más destacados discípulos valdesianos, Marco Antonio Flaminio, fue el responsable de una influyente poetización horaciana de los salmos: In librum psalmorum brevis explanatio (París, 1546), publicado a la muerte de Valdés ${ }^{20}$. Además, dentro de la producción valdesiana, nítidamente religiosa, traducir los salmos suponía acercarse a uno de los libros bíblicos (junto con Job y el Cantar de los cantares) de carácter literario, por lo que este resulta de alguna forma el escrito más literario de Valdés, que ya había mostrado su sensibilidad hacia la literatura dentro de las reflexiones que hay en la parte final del Diálogo de la lengua.

\section{El Salterio valdesiano}

\subsection{Testimonio y ediciones}

La traducción que Valdés hizo de los Salmos y los comentarios que realizó sobre ella nos son conocidos a través de dos manuscritos conservados en la Biblioteca Nacional Austriaca con sede en Viena: en uno está la traducción y en otro el comento.

${ }^{20}$ Margherita MoRreale ( «Juan de Valdés traducteur de la Bible: théorie et pratique à travers la version du Psaume 17 (18)», en L'humanisme dans les lettres espagnoles, ed. Agustín Redondo [Paris: Librairie Philosophique J. Vrin, 1979] págs. 65-86: 86, n. 49) señala claramente la influencia valdesiana sobre Flaminio, y aduce, refiriéndose a la obra del italiano: «cet ouvrage mériterait d'être étudié à cause de ses ressemblances avec les Psaumes valdésiens [...] La structure quelque peu apodictique (souvent lourde dans ses parallelismes et antithèses) qui caractérise la prose de Valdés dut influencer sensiblement sa doctrine». 
El manuscrito de la traducción valdesiana ${ }^{21}$ carece de atribución de autoría y fue identificado por Boehmer a través de su dedicatoria ${ }^{22}$. Por su parte, el manuscrito del comentario ${ }^{23}$ conserva los comentarios a los Salmos del primer libro (esto es, hasta el 41) ${ }^{24}$.

Sabemos por los inventarios de la biblioteca imperial que el Salterio valdesiano está allí al menos desde 1576 , de lo que Boehmer ${ }^{25}$ coligió una posible pertenencia «a Maximiliano II, el cual, antes de ser emperadór, recibió el comentario de Valdés sobre la primera epístola a los Corintios, que le dedicó el editor Juan Pérez». La hipótesis tiene el atractivo de situar a Valdés como lectura libresca de Maximiliano II de Habsburgo y al protestante cordobés Juan Pérez de Pineda como intermediario. Ninguna de las dos conjeturas parece descabellada. Fue Maximiliano II monarca de claras simpatías luteranas a quien Alfonso de Valdés resultaba conocido en tanto que su tío y suegro, el emperador Carlos V, había tenido a Alfonso de Valdés como secretario, y este Valdés había muerto de forma repentina por la peste justamente en un lugar de su territorio imperial, Viena, en 1532. Es a este Maximiliano de Austria al que Juan de Valdés le dedica su comentario a la primera epístola de san Pablo a los corintios. Por su parte, Juan Pérez de Pineda fue él

${ }^{21}$ El Salterio traduzido de el Hebreo en Romance Castellano; manuscrito 11712 de la Öesterrechische Nationalbibliothek, Codex Vindobonensis Palatinus 11712. El nombre de la dedicataria está tachado pero es reconocible.

22 Vid. Eduard Boenmer, El Salterio traduzido del hebreo en romance castellano. Ahora por primera vez impreso (Bonn: Imprenta de Carlos Georgi, 1880 [Reimpr. Barcelona: Librería de Diego Gómez Flores, 1983. Colección Reformistas Antiguos Españoles XXIII]).

${ }^{23}$ Muy difícilmente localizable, ya que su referencia no se encuentra mencionada en ninguna de las ediciones modernas disponibles y tampoco el archivo que lo guarda lo ha catalogado con alusión a Valdés. Tras varias pesquisas, hemos podido comprobar que se trata del manuscrito de la Österreichische Nationalbibliothek Codex Vindobonensis Palatinus 11853, con título Commentarius in prios quadraginte psalmos Davidicos, de 201 folios.

24 El primer editor de los Comentarios de Valdés a los Salmos, Manuel CARrasco (Joya literaria. Comentario a los Salmos escrito por Juan de Valdés en el siglo XVI), daba por hecho en su introducción que el comentario a los Salmos se concibió y escribió como una glosa completa a absolutamente todos los salmos y no solo a su primera parte, pero que se habrían perdido los comentarios del salmo 42 en adelante.

25 Apud Boenmer, El Salterio traduzido, pág. 174. 
mismo también autor en 1557 de una versión traducida de los Salmos que dedicó a la hermana del emperador, María de Austria, tía homónima de la mujer de Maximiliano.

Aunque es imposible reconstruir el recorrido del Salterio de Valdés desde Nápoles a Viena, podemos apoyarnos en los datos de Lopez ${ }^{26}$, quien ha mostrado cómo Mario Galeota acogió y distribuyó desde Nápoles la obra valdesiana ${ }^{27}$. Sin duda está en esa mano intermediaria el envío al emperador Maximiliano, tal vez con el calvinista Juan Pérez de Pineda como corresponsal o tal vez como mero lector. No hay certeza de si Pérez de Pineda leyó alguna vez la traducción del Salterio valdesiano ${ }^{28}$. Tampoco hay rastro que nos permita concluir si fueron alguna vez leídos en España, probablemente no.

Pese a su conservación separada, es posible pensar en una realización simultánea de ambos cuerpos textuales que podrían datarse a través de diversos indicios. Nieto ${ }^{29}$ fechaba la traducción en torno a 1537 , con el argumento de que Valdés muere en 1541 y esta fue su primera obra napolitana. Aunque no puede afirmarse con seguridad, el Diálogo de la lengua sería anterior a los Salmos valdesianos.

La obra valdesiana tuvo una suerte irregular hasta época moderna. La escrita en España se persiguió hasta hacerla prácticamente desapa-

26 Vid. Pasquale Lopez, «L'oficina napoletana del valdesiano Galeota», en Doce consideraciones sobre el mundo hispano-italiano en tiempos de Alfonso y Juan de Valdés, eds. y coords. Francisco Ramos Ortega et alii (=Anexos de Pliegos de Cordel I [Roma; Instituto Español de Lengua y Literatura de Roma, 1979]) págs. 209-223.

27 De hecho, en la sentencia inquisitorial por la que se le inculpa en 1567 declara explícitamente «haver tenuto, letto, tradutto et laudato con diversi, et in varii tempi, et fatto trascrivere alcuni libri del quondam Giovanni Valdesio, cioè il commento suo sopra San Mattheo, sopra li salmi, le perconte [preguntas] con certe epistolette, l'Alfabeto Christiano»; apud Lopez, «L'oficina napoletana del valdesiano Galeota», pág. 220.

28 Ricart (Juan DE VALDÉs, Diálogo de doctrina christiana y el Salterio traducido del hebreo en romance castellano, transcripción, introducción y notas de Domingo RICART [México D.F.: UNAM, 1964] pág. 8) apuntaba a esa posibilidad, que Menéndez Pelayo había descartado. Para NieTo, El Renacimiento y la otra España, pág. 448: «es ciertamente improbable que si Pérez tuviese en sus manos la traducción del Salterio de Valdés, que no la hubiese publicado como hizo con los dos Comentarios».

29 Apud Nieto, El Renacimiento y la otra España, pág. 512. 
recer (como el Diálogo de doctrina cristiana, del que solo se conserva un ejemplar que localizó Marcel Bataillon en Portugal) y la escrita en Italia circuló en vida del autor solo en forma manuscrita. A su muerte, se publican la Instrucción cristiana para niños (ca.1540), segundo catecismo valdesiano, el Alfabeto cristiano (1545); los Cinco trataditos (1545); las Ciento diez divinas consideraciones y santas meditaciones (1550) y, por parte de Juan Pérez de Pineda desde la imprenta heterodoxa que organiza en Ginebra para la introducción en España de libros vedados, los Comentarios a la Epístola de San Pablo a los romanos (1556) y los Comentarios a la epístola I de San Pablo a los Corintios (1557). Otras obras valdesianas tuvieron que esperar al siglo XVIII para conocer difusión impresa, como su célebre Diálogo de la lengua (1736).

La obra que aquí nos ocupa, el Salterio en romance, se publicó por primera vez en 1880 y los Comentarios a los Salmos cinco años más tarde. La traducción de los versos bíblicos fue editada por Boehmer en 1880 y luego por Ricart ${ }^{30}$; la edición de Boehmer utiliza de forma peculiar la ortografía preceptuada por Valdés en su Diálogo de la lengua, como hizo en la edición que del propio Diálogo sacó en 1895. Por su parte, los comentarios a los Salmos fueron editados de forma separada en el ejemplar de 1882 de Revista Cristiana. Periódico científico religioso ${ }^{31}$ y otra edición apareció en 1885 en Madrid (Librería Nacional y Extranjera ${ }^{32}$ ) al cuidado de Manuel Carrasco y con título

30 Vid. DE VALDÉs, Diálogo de doctrina christiana y el Salterio traducido del hebreo en romance castellano.

${ }^{31}$ La referencia concreta remite a estas páginas: 153-157, 167-170, 184-186, 204$206,305-308,362-364$ y 355-357. Sin descartar otras ubicaciones, la publicación se puede encontrar en la Biblioteca Nacional de España.

${ }^{32}$ La editorial del libro fue fundada por el pastor protestante de origen alemán Friedrich Fritz (Federico Fliedner, 1845-1901). Su firma aparece al principio de los dos primeros tomos de los fondos de la Revista Cristiana conservados en la BNE. Estos números llegaron en el XIX a la Nacional, pero no existen registros que confirmen si fue mediante donación de Fliedner. Señalemos que la colección de la revista está incompleta en la BNE, faltan años enteros y en el tomo de 1897 ya no hay firmas. Por otra parte, la edición de Carrasco fue costeada también por Fliedner, quien «ya había patrocinado el comentario de Valdés al Evangelio de San Mateo; debido al gran interés que Fliedner tenía de dotar al protestantismo español de ediciones de teólogos autóctonos españoles» (apud Carlos López Lozano, Juan de Valdés, Comentario a los 
introductorio Joya literaria. Comentario a los Salmos escrito por Juan de Valdés en el siglo XVI y ahora impreso por primera vez. Esta edición fue promovida, como declara el propio Carrasco en la introducción («Al lector»), por Boehmer, quien facilitó a Carrasco el manuscrito vienés de los comentarios y la copia del manuscrito del Salterio que había realizado la esposa de Boehmer ${ }^{33}$. La edición tiene las grafías y las formas verbales modernizadas. Tras esta edición, aparece una traducción al inglés hecha por John T. Betts publicada en 1894 (Commentary on the first book of Psalms, Londres: Ballantyne, Hanson \& Co). No hay propiamente nuevas ediciones en español posteriores a la de Carrasco, ya que la realizada por Carlos López Lozano (Terrassa: Libros CLIE, 1987) reproduce fotográficamente la de Carrasco con una introducción de apenas tres páginas. Esta es la que resulta más fácilmente consultable hoy ${ }^{34}$.

Prólogo, comentarios y traducción merecen un análisis textual conjunto, ya que presentan (sobre todo el prólogo y los comentarios, libres

Salmos [Terrassa: Libros CLIE, 1987] nota 6; esta edición es una reimpresión de la de Carrasco con una introducción inicial a cargo de López).

33 Boehmer llegó a tener en su domicilio los propios manuscritos vieneses de Valdés. Dice Carrasco (Joya literaria. Comentario a los Salmos escrito por Juan de Valdés en el siglo XVI) en su introducción: «recibí en Ginebra, en Setiembre de 1879, una carta del ilustre catedrático [Boehmer] en la que hacia [sic] el honor de proponerme el preparar y editar este manuscrito. Dos dias [sic] despues [sic] llegaba yo á Estrasburgo, en donde él residia [sic], y á donde me habia mandado él traer todos los manuscritos». La vinculación de Boehmer con Valdés se da a través del concurso imprescindible de Benjamin Wiffen; el británico, que había colaborado durante años con el polígrafo español Luis de Usoz, patrocinador de la Colección de Reformistas Antiguos Españoles que publicó Wiffen, no vio culminado en vida su propósito de reeditar los clásicos de protestantismo español, y «sus albaceas testamentarios entregaron todo ese valioso e inmenso material, en buena parte ordenado y anotado por el propio Wiffen, la obra de su vida, al hispanista alemán Edward Boëhmer [...] quien lo dio a las prensas en tres gruesos volúmenes entre 1874 y 1904 con el título de Bibliotheca Wiffeniana. Spanish Reforms of Two Centuries from 1520; vid. VILAR y VILAR, El primer hispanismo británico, pág. 51. El Comentario al Evangelio de San Mateo de Valdés, que Boehmer publica, fue proyectado dentro de la colección original dirigida por Wiffen y Usoz.

${ }^{34}$ Cito el comentario con número de página a partir de esta edición. Para la traducción de los Salmos sigo la edición de Ricart. Carrasco, obviamente, usa la edición de Boehmer como fuente de los Salmos que Valdés comenta. 
de sujeciones a la letra) datos de interés sobre la forma de desarrollar un proceso de trabajo traductológico.

\subsection{La introducción del Salterio valdesiano: decisiones traductológicas}

La introducción de la obra contiene datos de gran interés sobre la actitud y forma de traducir, así como del cuidado formal con que Valdés planeó su traducción de los Salmos. Se aprecian en esas páginas iniciales cinco grandes bloques de contenido.

En el primero, Valdés reflexiona sobre las virtudes de la piedad y la justicia, así como sobre la variable forma en que los hombres cultivan ambas virtudes en relación con la vida celestial. En una segunda parte, aconseja sobre la conveniencia de los Salmos para la práctica de ambas virtudes. En el tercer bloque, Valdés encomia los Salmos por encima de otros libros bíblicos, particularmente contrastándolos con las cartas de san Pablo y situando las composiciones davídicas por encima de las cartas paulinas; y ello aunque san Pablo es para Valdés, como afirma Del Olmo Lete, su «mentor ineludible» ${ }^{35}$. Posteriormente, en el bloque cuarto, advierte sobre distintas decisiones de índole formal y lingüística que afectan a su traducción del Salterio. Son, como él mismo alude, «avisos cuanto a la letra» de la traducción. Por último, en el quinto bloque, hace diversas aclaraciones sobre el espíritu de la letra y en qué sentido se debe entender la doctrina de los Salmos, proponiendo una interpretación alejada de lo hebraico; afirma: «este tiempo no es tiempo de ley sino de Euangelio», ya que, según él, en el libro veterotestamentario: «muchos afettos y muchos concettos espiritualíssimos y diuiníssimos del todo conformes a los del espíritu del Euangelio» se contienen. No integra ningún bloque, por su escasa extensión formal, la breve apostilla que se sitúa tras el bloque quinto, en la que Valdés avisa de que el adje-

35 Gregorio del Olmo Lete, «La Biblia en la literatura espiritual del Siglo de Oro», en La Biblia en la literatura española. II. Siglo de Oro, dir. G. Del Olmo LeTe, y coord. Rosa NAvarro Durán (Madrid: Editorial Trotta-Fundación San Millán de la Cogolla, 2008) págs. 101-180: 130. 
tivo pobreto que se usa en la traducción puede ser preterido en favor de afligido $^{36}$.

Nos interesan especialmente los dos bloques pares de la estructura introductoria, que giran en torno a hechos de hermenéutica textual y traductológica, y son los que nos proporcionan información de mayor interés para entender los modos de Valdés y su punto de vista sobre algunas cuestiones de lengua. Es en esta parte donde Valdés explica por qué en su traducción ha partido del hebreo:

(3) $\mathrm{Y}$ entendiendo tambien que, assy como para conozer a Dios, es menester conocer primero a Christo; assy para entrar en la piedad y crecer en ella es menester entrar primero en la justificacion y crecer en ella; lo qual he dexado de hazer, tanto porque entiendo que los Salmos tienen mas necessidad de buena traslacion que las Epistolas, por estar ellos en los libros latinos mas impropiamente trasladados que no estan ellas, quanto porque entiendo que siendo mas natural al hombre la piedad que la justificacion (pág. 135).

Existía en el XVI un cierto prejuicio contra las versiones que circulaban de los Salmos ${ }^{37}$ y parece que Valdés se apoya en él para rechazar las versiones canónicas venidas del latín y así justificar una nueva empresa de traducción al romance hecha desde el hebreo. Emprende esta tarea sin estar vinculado ni a la tradición rabínica ni a un círculo intelectual de teología universitaria, por eso es legítimo preguntarse cuál es la fuente y el grado de conocimiento del hebreo que permitió a Valdés traducir el libro bíblico. Nieto (pág. 103) apunta a la posibilidad de que aprendiese esta lengua de Alonso de Zamora en el entorno universitario de Alcalá, donde coincidiría con la enseñanza de escrituras de Cipriano de la Huerga, estudioso de la Biblia hebrea que también

${ }^{36}$ Esta forma figura en la traducción y en el comento: Porque no será hasta el fin olvidado el pobre, ni la esperanza de los pobretos perecerá para siempre. [...] Adonde entiendo que llama pobres y pobretos á los píos; porque dependiendo de Dios, han renunciado á todo el favor que les puede venir de las criaturas (Salmos 9,13; en la edición de Ricart corresponde a IX, 20).

37 Recordemos que en 1509 Lefèvre d'Etaples había publicado Quincuplex Psalterium, gallicum, romanum, hebraicum, vetus et conciliatum con cuatro versiones distintas del Salterio (y una quinta conciliada, emanada de las previas) tomadas de las anteriores, de las que una es la hebrea. 
se interesó por los $\operatorname{Salmos}^{38}$, y donde estaría bajo el influjo de Pedro Ruiz de Alcaraz, pero reconoce que pudo haber otros estímulos para el manejo del hebreo, como la propia genealogía del humanista («es posible que siendo Valdés de origen converso por parte de madre y padre que ya supiese suficiente hebreo antes de ir a Alcalá» ${ }^{39}$ ) y, obviamente, su inserción en círculos erasmistas que manejaban las tres lenguas clásicas.

También en el segundo bloque de la introducción Valdés declara el uso de tinta de dos colores en el original para separar lo propio de lo ajeno en el cuerpo de la traducción:

(4) He mezclado del mio algunas palabras a fin que la letra lleue mas lustre, vaya mas clara y mas sabrosa. Estas, porque sean conocidas, van escrittas con tinta colorada, pretendiendo que se les ha de dar el credito que se deue dar a palabras de hombre, haziendo diferencia entre ellas y las que son de Spiritu Santto. Es bien verdad que, por la mayor parte, las palabras que van escrittas con tinta colorada se entienden de suyo en la letra hebrea (pág. 135).

Esta exigencia material es consecuencia del trabajo exegético requerido por los Salmos, ya que estos, independientemente de que se leyesen en una versión latina, hebrea o romance, tienen un carácter fuertemente elíptico y una clara tendencia a la implicitud; por eso, la brevedad de la forma salmódica obliga a la apostilla, la glosa, el comentario que recupere el contexto extraviado o la utilización en la propia versión traducida de palabras no contenidas en la fuente. En el testimonio que nos ha llegado se mantiene el uso de esa doble tinta, marcación escrupulosa que nos invita a considerar como apógrafo al testimonio vienés.

La cuestión material del doble color emana de una declaración anterior mucho más relevante a efectos de reconstrucción de la ideología valdesiana sobre traducción, donde se declara haber abrazado una opción traductológica consistente en ir palabra por palabra, con la consecuente

${ }^{38}$ Con todo, las obras sobre los salmos de Cipriano de LA Huerga se publicaron tardíamente ya que este rechazó en un principio la opción de que circulasen impresas; sí permitió publicar las declaraciones de los salmos: Commentarius in Psalmum CXXX (Lovaina, 1549 y Alcalá, 1555) y Commentarius in Psalmum XXXVIII (Alcalá, 1555).

39 Mismo origen hebreo se ha señalado para otros traductores de esa lengua que trabajaron con versiones de la Biblia, como Nicolás de Lira. 
resonancia jeromiana que evoca tal método, también enarbolado en los preliminares de la Biblia de Ferrara:

(5) Considerando yo todo esto, y desseando ayudar con mis flacas fuerças a Vuestra Señoria en esta su aplicacion a la piedad y a la justicia, y por ella, y con ella a algunas otras personas en quien conozco esta mesma aplicacion; y pareciendome que para hazeros muy pia os seruira mucho la licion de los Salmos de Dauid, os los he puesto en romance castellano, sacandolos de la letra hebrea, e asy palabra por palabra, en quanto lo ha sufrido el hablar castellano. Y aun me he atreuido mas vezes a la lengua castellana, hablando impropiamente, que a la hebrea, alterandola. Esto he hecho assy, pareciendome cosa conueniente y justa que las cosas escrittas con Espiritu Santto, sean tratadas con mucho respeto (págs. 134-135).

Con todo, y como se muestra también en los comentarios, la traducción valdesiana del Salterio dista de ser una traducción comparable a las medievales y parece asimilarse ya mejor a las traducciones humanistas. Como veremos, Valdés se mantiene muy fiel al texto fuente, incluso forzando soluciones lingüísticas poco naturales en la lengua de destino por tal de hacerse eco de la estructuras hebraicas en quanto lo ha sufrido el hablar castellano.

Por su parte, el bloque cuarto contiene avisos quanto a la letra de gran interés tales como la especificación del procedimiento que se ha seguido en la titulación de cada salmo, la inserción de la palabra sela a fin de verso en algunos casos, los problemas que plantea la traducción del nombre de dios en hebreo, griego y latín, el recurso a Señor y señor (distinguiendo Valdés entre capitales y minúsculas) según los contextos, la traducción del vocablo hombre del hebreo así como determinados usos lingüísticos hebraicos: el empleo de futuro por imperativo o pretérito, el pretérito por futuro o la posibilidad de usar en hebreo el singular como alusión a un referente plural, asunto que también aparece en el Diálogo de la lengua cuando Valdés se refiere a las semejanzas entre el castellano y la lengua hebraica ${ }^{40}$.

40 De hecho, Morreale ( Juan de Valdés traducteur de la Bible», n. 24) advierte de la insistencia valdesiana sobre este tema, que menciona en la dedicatoria y en alguno de los comentarios a Salmos. 
Algo se echa en falta en esta introducción: la apología del castellano como lengua capacitada para acoger la palabra divina. Ello contrasta con otras traducciones de libros sagrados que se esfuerzan en aclarar el porqué de la apuesta por el vernáculo en lugar de la lengua de la fuente en una etapa donde es sospechosa, si no directamente condenable, la traducción de la Biblia. La hipótesis de Nieto ${ }^{41}$ es que Valdés ya había hecho una apología del castellano, que sería el propio Diálogo de la lengua, lo que excusa que Valdés en el Salterio defienda al castellano como lengua para la lectura bíblica en tanto que además, Valdés, según Nieto, «no pensaba publicar el libro, por consiguiente holgaban explicaciones las cuales Julia [Gonzaga] bien sabía como resultado de sus diálogos y conversaciones sobre tal tema». La defensa que Valdés hace del vulgar se observa también en el hecho de que, más allá de alguna carta misiva, no tenemos obra latina de Valdés. Su visión de la religión se sostiene en la interpretación directa del texto, al que el vulgar da un acceso más directo ${ }^{42}$.

\subsection{Los comentarios: datos lingüisticos}

Junto con la introducción y la propia traducción, el tercer cuerpo textual que podemos considerar dentro de la traducción valdesiana de los Salmos es el de los comentarios que hace el autor al texto. A diferencia de otros comentarios sobre los Salmos publicados en el Xvi ${ }^{43}$, los de Valdés son muy extensos; esa labor de comentar parece ligada a la de la traducción, ya que Valdés también comentó del Nuevo Testamento el Evangelio de san Mateo y perícopas aisladas de Romanos I y Corintios. La forma de acercarse a los textos que tiene Valdés, su discurso de fuerza como intérprete, validador o allegador de los escritos y palabras ajenas, hace legítimo pensar que su intencionalidad primera es más la de comentar pero que,

41 Nieto, El Renacimiento y la otra España, pág. 509.

42 Vid. al respecto Todd Schmid, «The linguistic and translation theory of Juan de Valdés», Romance Notes 48 (2008) págs. 355-364: 361.

${ }^{43}$ Como la Exposición moral del psalmo LXXXVI de Jorge de Montemayor (1548), los comentarios a dos salmos hechos por fray Luis de León o el de un salmo incluido por Pedro de Alcántara en su Tratado de la oración (1556). 
para hacerlo sobre un material que le resulte fidedigno y efectivo, necesita desarrollar en primer lugar un proceso de traducción.

Los comentarios que hace Valdés a su traducción son muy informativos. En lo que se refiere al tipo de hermenéutica bíblica desplegada, coinciden con la tipología de comento que hace a las cartas paulinas y al evangelio de Mateo ${ }^{44}$ : no estamos ante un comentario intelectual, lleno de citas eruditas de otras obras bíblicas. Se hace una exégesis del texto basada principalmente en la glosa lingüística, falta la glosa escolástica, el comentario es más humanístico que medieval y tiene al texto como centro y no como excusa para la exégesis. Por ello, lo que el autor concibió como un complemento a la comprensión de los Salmos y una guía para la buena orientación del contenido veterotestamentario se convierte a los ojos del analista actual en un repertorio de los aspectos que, en tanto que explicados, debieron de ser a la luz de Valdés los elementos más necesitados de análisis dentro del libro bíblico y aquellos en que él se consideraba más versado como intérprete de lengua y de contenido. Morreale, que estudió uno de los Salmos traducidos por Valdés junto con su comentario asociado ${ }^{45}$, enfatizaba el hecho de que en los comentarios valdesianos hay una nueva traducción de los Salmos sumada a la traducción propiamente dicha, ya que en esta se atiende al texto hebreo fuertemente mientras que en el comentario se introducen versiones que no se relacionan tanto con el original sino con la comprensión del lector: «les versions contenues dans le comentaire permettraient de voir en quoi le texte qu'il donne correspond à l'original, mais aussi de percevoir comment s'exprime la langue "vulgaire" quand elle est libre des entraves de la traduction-calque».

Por otra parte, resultado del diálogo entre la propia traducción y sus comentarios es el hecho de que en una misma obra terminen conviviendo lo que Ricart (pág. 14) calificaba como «los dos tipos de prosa más característicos de Valdés: en la dedicatoria-prólogo, la prosa periódica [...] y en los Salmos, la prosa [...] robusta, sintética, expresiva y desnudamente clásica» que según este autor «no se amolda a ninguna forma retórica ni tuvo imitadores», y junto a ambos modelos, el molde expo-

\footnotetext{
44 Apud Del Olmo Lete, «La Biblia en la literatura», pág. 133.

45 Morreale, «Juan de Valdés traducteur de la Bible».
} 
sitivo, armado de cierta retórica formulística en la introducción de explicaciones, con el que se construye la red de comentarios de los Salmos. Nos referimos a estructuras como:

(6) En el verso cuatro, por limpias palmas se entiende la limpieza de las obras exteriores, y por puro corazón, entiendo la pureza de los pensamientos y de todas las cosas interiores. Y á lo que dice que no toma en vano el ánima mía, dan diversas exposiciones, porque también los libros hebreos leen ánima mia y ánima suya. Yo pienso que habiendo dicho David, que tales deben ser las obras y que tales los pensamientos del que había de estar en el tempo de Dios, con estas palabras, muestra que tales habian de ser las palabras, diciendo que debian ser tan ajenas de los juramentos que los hombres hacen, que ni aun por mi ánima dijesen, sin haber por qué decirlo. En esta sentencia vendrá así bien decir el ánima mía, como decir el ánima suya. Esto mismo se confirma... (pág. 134).

Los comentarios valdesianos suelen atender a cuestiones de hermenéutica del sentido religioso de las frases de cada salmo y a su aplicación dentro de una perspectiva cristiana que es posterior a la del Antiguo Testamento. La actualización de los valores hebreos de los Salmos a la luz de la aceptación de Cristo como Mesías es un objetivo persistente en la glosa valdesiana, pero se construye haciendo central a la idea religiosa y sin intencionalidad (y seguramente, sin posibilidad) de reconstruir el contexto cultural perdido. Por eso, vemos que es escasísima en los comentarios la explicación amplificatoria de tipo enciclopédico que, en todo caso, está al servicio de una aclaración lingüística de un pasaje que puede ser oscuro o llamativo para el lector del XvI:

(7) Oprimido y acoruado estoy muy mucho, todos los días ando enlutado [...] Cuanto a lo que dice en el verso seis que andaba en luto, ya está dicho que acostumbraban los Hebreos traer luto en sus enfermedades (Sal 38,7; Comentario, pág. 225).

(8) En el verso dos, diciendo cuando alzo mis manos, habla como hebreo, a quien pertenecían estas señales de adoración exterior. El cristiano adora en espíritu y en verdad (Sal 28,2; Comentario, pág. 155).

En cambio, es muy frecuente en el comentario valdesiano la apostilla explícitamente lingüística, que, con todo, no es superior ni en número ni mucho menos en extensión a las consideraciones propiamente religio- 
sas y espirituales. En nuestro análisis hemos podido separar los siguientes cuatro tipos de reflexiones de índole lingüística dentro del comentario valdesiano:

a) El tipo de comento más frecuente es el que contiene aclaraciones a usos oscuros (generalmente por su sentido metafórico) que se localizan en los Salmos. Estos abundan en menciones conceptuales que necesitan aclaración para el lector del XVI, a quien Valdés, con estructuras como por $X$ entiende o vale tanto ofrece una explicación:

(9) Porque conoce el SEÑOR el camino de los justos. [...] Adonde por camino entiende su manera de vivir, sus diseños y sus costumbres (Sal 1,6; Comentario, pág. 19).

(10) ¿Por qué se alborotan gentes, y pueblos imaginan vanidad? [...] En el verso primero, por gentes y por pueblos, pienso que entiende David á los vulgares hebreos que se armaban contra él (Sal 2,1; Comentario, pág. 20).

(11) Hijos de varones; ¿hasta cuándo irá mi gloria en vituperio? [...] En el segundo verso, habla David con los que eran principales en el pueblo de Israel, á los cuales llama hijos de varones, que vale tanto como hombres principales (Sal 4,3; Comentario, pág. 31).

(12) Destruirás a los que hablan mentira, al varon de sangres y engañoso aborrecerá [...] Por varón de sangres entiende hombre sangriento, tacaño y abellacado (Sal 5,7; Comentario, pág. 35).

(13) Y aparejarale vasos de muerte, fabricará sus saetas para perseguidores [...] Por vasos de muerte entiende instrumentos mortales. Diciendo fabricará sus saetas para perseguidores, entiende que Dios va aparejando instrumentos con que castigar a los impíos enemigos de los píos (Sal 7,14; Comentario, pág. 47).

(14) Cuerdas en repartimiento me han caido en partes apacibles [...] $\mathrm{Y}$ dice cuerdas, entendiendo la manera con que antiguamente los que ganaban una provincia, repartian entre sí las tierras de ella (Sal 16,6; Comentario, pág. 83).

b) Otra clase de comentario que se repite está ligado a usos concretos de la lengua hebrea mantenidos en la traducción y que resultan oscuros, por lo que Valdés se ve obligado a aclararlos ${ }^{46}$ :

${ }^{46}$ La mención contrastiva a lo castellano, al contrario, es muy escasa y prácticamente se limita a este único pasaje: «Tienen el riñon encubierto con su boca hablan 
(15) El que me libró de mis enemigos, y aún me ensalzó sobre los que se levantaron contra mí. Del varón falso me escapaste [...] Adonde por varon falso pienso que entiende á Saul; también puede ser que use de número singular por plural, y que diga. de hombres falsos y mentirosos me libraste (Sal 18,49; Comentario, pág. 106).

(16) Dijiste ánima mia, al Señor. Tú eres mi Señor, mi bien no para ti. [...] En el verso dos se añade aquel ánima mia, porque aunque no está en la letra hebrea, se entiende en el dijiste que es femenino (Sal 16,2; Comentario, pág. 81).

(17) Levántate, Señor. Vale a la mano, abátelo; libra my ánima del impío, que es espada tuya. [...] Y es así que se sirve Dios de la impiedad de un impío para destruir á otro impío, y á las veces para corregir á un pío. En estos versos entiendo que usa de singular por plural (Sal 17,1; Comentario, pág. 90).

Referencias al hebreo similares figuraban también en el Diálogo de la lengua, por ejemplo incidiendo en el uso de singulares genéricos en hebreo en el mismo sentido en que vemos ese mismo aspecto gramatical aparecer en el último comento valdesiano citado ${ }^{47}$. El resto de menciones a la lengua hebrea se dirige a aclarar vocabulario que Valdés ha traducido de manera bastante fiel al original y que precisan de aclaración según la concepción valdesiana, desde formas de grave implicación religiosa (18), de entendimiento difícil (19 y 20), o a la que se añade alguna explicación adicional basada en el acercamiento al significado completo y los matices propios del vocablo hebreo (21 y 22):

soberbia. [...] Desde el verso diez comienza David á pintar á los que ha llamado impíos y enemigos. Primero dice que tienen el riñon cubierto, usando de una manera de hablar usada en Castilla; y es así, que cuando queremos decir que uno está rico y sin necesidad, decimos que tiene el riñon cubierto; y por lo que se sigue parece que entiende David que las riquezas hacian insolentes a los que lo perseguian» (Sal 17,10; Comentario, pág. 89). Ello parece confirmar nuestra idea ya formulada acerca de que Valdés parece prefiere adoptar idiomatismos hebreos antes que versionar por completo y más libremente la fuente para que suene totalmente castellana.

47 Así, leemos en el Diálogo: «Con la lengua hebrea se conforma la castellana en no variar los casos, porque en el singular tienen todos ellos una sola terminación, y en el plural otra, assí como bueno y buenos, hombre y hombres». 
(18) Pónense reyes de la tierra y príncipes conjuran á una, sobre el SEÑOR, y sobre su ungido. [...] Adonde se ha de entender, que por lo que nosotros decimos ungido, los griegos dicen Cristo y los hebreos $\mathrm{Me}$ sía (Sal 2,2; Comentario, pág. 20).

(19) Júzgame, sEÑor, conforme a mi justicia, y conforme a mi integridad, que está sobre mí. [...] aquello que está sobre mí (según el hablar hebreo) está puesto por abundancia (Sal 7,9; Comentario, pág. 46).

(20) Falsamente habla el varon con su projimo, con labios de lisonjas hablan de corazon y corazon engañosamente [...] aquello de corazon y corazon, segun el hablar de la lengua hebrea, quiere decir, falsa y fingidamente, con dobladura de corazon. Una manera de hablar semejante á esta se lee en el libro primero de los Paralipómenos 2. Dice labios de lisonjas por lenguas lisonjeras que hablan a sabor del que las oye (Sal 12,3; Comentario, pág. 67).

(21) Porque en su ira hay un momento y vidas en su voluntad [...] Y en aquello voluntad, el vocablo hebreo significa casi benevolencia (Sal 30,6; Comentario, pág. 164).

(22) a. Engrandecido sea el Señor, que quiere la paz de su siervo. [...] quiere decir, que quiere que su siervo viva en paz, con prosperidad, felicidad y contentamiento. Y todo esto entienden los Hebreos debajo del vocablo, que nosotros trasladamos paz. Con él se saludan cuando se topan, y de él usan en toda manera de salutación (Sal 35,27; Comentario, pág. 203).

b. Los cielos cuentan la gloria de Dios y el firmamento publica las obras de sus manos. En el verso primero entiendo que dice David, que la consideracion del maravilloso artificio que hay en los cielos trae a los hombres en conocimiento de la gloria que se debe dar a Dios [...] Por firmamento entiende el cielo que se ve; el hebreo lo llama extensión porque está extendido (Sal 19,2; Comentario, pág. $107)^{48}$.

${ }^{48} \mathrm{El}$ uso de firmamento (cultismo cuatrocentista desde el latín FIRMAMĔNTUM 'fundamento, apoyo') es explicado por Valdés partiendo del vocablo hebreo original (rāqīa 'extensión') y muy posiblemente interferido por la traducción de que de este se hizo en la Vulgata para traducir el griego bíblico $\sigma \tau \varepsilon \rho \varepsilon ́ \omega \mu \alpha$ 'firmamento', 'construcción sólida', «mal comprendido por los traductores, porque en siríaco significaba 'solidez'» (DCECH, s. v. firmamento). 
Asunto aparte es el de cuánto del hebreo de la fuente está volcado en el texto valdesiano. Morreale analizaba uno de los Salmos valdesianos y apuntaba a rasgos hebreos que se filtran: número y género, ausencia de artículo, infinitivos sustantivados. De manera directa o por todas las lecturas previas que ha hecho el autor de textos bíblicos traducidos, la impronta del original hebreo que se proyecta sobre el texto castellano se verifica en el hecho de que la versión romance guarde un rasgo como los sintagmas paronomásicos propios de la Biblia hebrea:

(23) Allí, en el conocimiento temerian temor, porque Dios está en generacion de justos. [...] Y aquellos temerian temor, es manera de hablar de lengua hebrea (Sal 14,5; Comentario, pág. 76).

c) Una tercera clase de comentarios se dirige a aclarar el significado concreto de términos que se utilizan en la traducción castellana; en esta clase de comentarios Valdés justifica sus decisiones lingüísticas neológicas. Por ejemplo, conmover, cultismo del Xv que aún no aparecía registrado en Nebrija ni Covarrubias, es palabra usada por Valdés, que se presta a traducirla; lo mismo ocurre con iniquidad, que en el XV se introduce como tímido neologismo y que Valdés no duda en utilizar, consciente de que en el comento habrá de explicarla mediante declaración expresa $(24,25)$ o meramente intercalando el sinónimo $(26,27)$ :

(24) Dios es justo juez, y se conmueve cada día. [...] Conmoverse es lo mismo que indignarse (Sal 7,12 Comentario, pág. 46).

(25) Por tu nombre, SEÑOR, perdonarás my iniquidad, porque grande es ella. [...] Y por iniquidad entiendo la malicia y malignidad humana por la depravacion de la naturaleza (Sal 25,11; Comentario, pág. 141).

(26) Acuérdese de todas tus ofrendas y encenice -convierta en ceniza- tus holocaustos. Sela (Sal 20,4; Comentario, pág. 166).

(27) Porque los pornas a una parte, endereçarás tus neruios -saetas- contra sus caras (Sal 21,13; Comentario, pág. 118).

d) Un último grupo de comentarios es conformado por aquellos pasajes en que Valdés deja huella de su trabajo traductológico a través de reflexiones sobre la dificultad de determinadas lecciones, la consulta de fuentes y versiones alternativas que ha desarrollado para contrastar su propuesta de traducción con otras previas y otras operaciones vinculadas a la textualización en castellano de los Salmos. Se refiere así a los in- 
térpretes previos (28), a las versiones latinas del Salterio en contraste con la hebrea que él maneja (29) y a las inteligencias o sentidos que se da a determinado pasaje (30).

(28) Los cuatro ó cinco versos que se sigue, entienden los intérpretes diferentemente; porque en ellos habla David de manera que las palabras están ambiguas y las sentencias dudosas. Como quiera que se entiendan, expresan bien la malignidad del impío (Comentario, pág. 58).

(29) Este verso tres alega San Pablo (Romanos 3. 12) contra los judíos, para mostrar que todos ellos se habian depravado. Nuestros libros latinos ponen aquí tres versos que no están en los libros hebreos, ni en los griegos (Comentario, pág. 75).

(30) Mirando a las obras del hombre, con la palabra de tus labios, he yo considerado los caminos del destruidor [...] Al verso cuatro dan diversas inteligencias porque en el hebreo está ambiguo y oscuro (Sal 17,4; Comentario, pág. 87).

Valdés, que con tanta certeza dictamina sobre el buen estilo y la propiedad en castellano en el Diálogo de la lengua, muestra claramente en su traducción de los Salmos la duda que le plantean algunos pasajes que resuelve con declarada inseguridad o ambivalencia de términos (3134); la disquisición sobre la fortuna exegética de pasajes concretos es común en las traducciones bíblicas por lo que esta clase de comentos es solidaria de otros textos bíblicos romances:

(31) Porque no desampararás mi ánima, en el infierno -o sepultura-. No darás a tu misericordioso á ver corrupcion -o fosa-. [...] en el verso décimo he dejado infierno, adonde segun la lengua hebrea, se podria decir sepultura; y he dejado corrupcion, adonde el hebreo propiamente dice $f o s a$; y tomando estos dos vocablos que signifiquen sepultura y fosa, será esta la sentencia de estos dos versos, que diga David así [...] (Sal 16,10; Comentario, pág. 84).

(32) Caualga sobre Cherubin y buela; buela sobre alas de viento. En el verso diez no entiendo en qué manera cabalga Dios sobre Cherubin, ni me satisface lo que entienden los que hacen profesion de entenderlo. [...] La causa porque se ha mostrado y ha hablado Dios con los hombres en nubes se puede congeturar, pero no sé si se puede saber de otro que del mismo Dios; y por tanto me remito á entenderla, 
cuando placerá a Dios que yo la entienda (Sal 18,11; Comentario, págs. 94-95).

(33) En la inteligencia del verso veintinueve hay mucha dificultad en la letra hebrea [...] Todo este salmo está lleno de divinos misterios, de altos conocimientos, y de entrañables afectos; de los cuales yo he notado los que he entendido y alcanzado; remitiendo al lector, que encomendándose á Dios, examine y escudriñe más; prometiéndole que si lo hace así, hallará muchas más cosas con tal pero, que lleve por guia al Espíritu Santo, que se alcanza creyendo a Jesucristo nuestro señor (Comentario, págs. 127-129).

(34) Estos tres versos, siete, ocho y nueve, están alegados en la epístola a los Hebreos, pero no segun la letra hebrea que aqui interpretamos, sino segun la griega que en tiempo de los Apóstoles era muy usada. Esto digo á fin de que no se maraville el lector, viendo esta interpretacion con aquella objecion (Comentario, pág. 240).

Incluyo, por último, en este grupo de comentarios, aquellos casos en que Valdés, a partir de su propia exploración en la lengua hebrea del Salterio, descarta la interpretación no cristiana que los hebreos han dado a pasajes de los Salmos que, según él, son anuncios proféticos de la venida de Cristo. La interpretación judía es, así, calificada de obstinada y falsa (35):

(35) Porque perros me tienen cercado; congregacion de peruersos me an rodeado; anme horadado mis manos y mis pies. [...] Diciendo anme horadado, puede ser que entendia «Ya en sus ánimos me tienen crucificado». Pero mejor es entenderlo, que haya tenido intento á lo que fue hecho en la persona de Cristo, del cual figura David, y al cual parece haber tenido delante sus ojos en este salmo. Los judíos nos calumnian aquí, diciendo que la letra hebrea no hace mencion de horadar; y dicen que dice: «Como leon mis manos y mis pies»; á los cuales responderé dos cosas: la una, que es tan conforme en la letra hebrea decir como leon, que decir horadaron, que fácilmente lo han podido ellos depravar. Y la otra, que ya que se leyese como ellos quieren, está bien esto aplicado á Cristo. Siendo así, que diciendo así como leon, es menester añadir algun verbo, el cual está bien que sea el que dice nuestra letra. De manera que diga, como leon me han horadado mis manos y mis piés. Pero, ¿quién puede bastar á convencer la obstinencia de un ánimo empedernido en falsa opinión? (Sal 22,17; Comentario, pág. 124). 
El denuesto a los judíos por sus falsas interpretaciones es interesante por lo declarado y abierto de su tono, que contrasta con la sorna con que se desliza algún chiste sobre los judíos en el Diálogo de la lengua y da la réplica, a saber en qué sentido, a la sombra de hebraizante que se proyecta en la genealogía valdesiana.

\section{El Diálogo de la lengua en el Salterio}

Por último, me ocupo en este trabajo de la lengua del Salterio en relación con la obra específicamente metalingüística de Valdés, el Diálogo de la lengua (en adelante, $D L$ ). El contraste nos permitirá elucubrar la fidelidad de la copia conservada con respecto al original controlado por Valdés y también estudiar el propio seguimiento que hace Valdés de las elecciones de morfología y léxico que alaba explícitamente en el $D L$.

\subsection{Usos gráficos y fonéticos cotejados}

Es arriesgado examinar los usos gráficos del manuscrito del Salterio, no autógrafo, en tanto que, como sabemos, en las grafías tenemos el nivel de intervención más común del copista respecto a su modelo; con todo, es preciso anotar la existencia de bastantes correspondencias entre lo prescrito y lo descrito por Valdés en este ámbito, ya que algunas preferencias gráficas valdesianas resultan muy constantemente respetadas en la copia austriaca del Salterio. Así, si el personaje de Valdés dice en el Diálogo preferir las grafías con labial implosiva conservada a las correspondientes palabras con vocalización y simplificación, en el manuscrito salmorial se respeta esa labial (36b):

(36) a. a mi ver los vocablos están más llenos y mejores con la $b$ que sin ella, y porque toda mi vida los he scrito y pronunciado con $b(D L$, pág. 169) 49.

b. cibdad (Sal 31,22; 48,2, 3, 9, 10; 59,7 etc.); bibda (Sal 94,6 y 146,9); cabdales (Sal 74,15).

49 Las citas del Diálogo de la lengua se harán por la edición de Cristina BARBOLANI (Madrid: Cátedra Letras Hispánicas, 1998). 
También en el nivel de la variación vocálica suele coincidir lo usado en el manuscrito con lo que Valdés preconiza en el Diálogo. Así lo comprobamos en pares del estilo vanedad-vanidad y otros con alternancia $o-u$ :

(37) a. en todos essos pongo yo siempre $i$ y no $e$, porque me parece mejor; y porque siempre lo he usado assí, y veo que los más primos en el escrivir hazen lo mesmo ( $D L$, pág. 160).

b. vanidad (Sal 2,1, 4,3 y 5,5), vanidades (Sal 31,7).

(38) a. [al respecto de abondar, abundar; ruido, roído; cubrir, cobrir] yo siempre scrivo la $u$, porque la tengo por mejor; creo hazen assí los más ( $D L$, pág. 166).

b. abundantemente (Sal 31,24); abundancia (Sal 37,16 y 49,7); ruido (Sal 38,9 y 65,8); cubrirán (Sal 65,14); cubrirá (Sal 73,6), cubrió (Sal 78,53).

Distinciones muy sutiles y frágiles de conservar en un proceso ulterior de copia también parecen haberse respetado, como en el caso de la oposición entre las formas esperar y asperar, variables que prácticamente eran intercambiables en español pero que Valdés diferencia sostenido en un contraste con fundamento en el italiano. Valdés separa asperar como 'aguardar a algo concreto' (el equivalente al italiano aspettare) y esperar como 'tener esperanza' (italiano sperare) (39). En el Salterio se observa un masivo uso de asperar como 'aguardar' con objeto directo marcado con o sin preposición $a$ (39b); esto contrasta con el exiguo empleo que se detecta de la forma paralela esperar (solo tres ejemplos, 39c), ligada a la preposición en:

(39) a. M.: ¿hacéis alguna diferencia entre asperar y esperar?

V.: Yo sí, diziendo asperar en cosas ciertas, y esperar en cosas inciertas, como vosotros usáis de ASPETTARE y SPERARE, y assí digo: «aspero que se haga hora de comer» y digo: «Espero que este año no avrá guerra». Bien sé que pocos o ninguno guarda essa diferencia, pero a mí me ha parecido guardarla, por dar mejor a entender lo que scrivo ( $D L$, pág. 181).

b. Tampoco queden auergonçados todos los que te asperan; queden auergonçados los que preuarican sin causa (Sal 25,3) \|| Encaminame en tu verdad y enséñame, porque tú eres Dios de my salud; a ti he asperado cada dia $($ Sal 25,5) $\|$ Perficion y rettitud me man- 
tengan, porque te he asperado (Sal 25,21) \| Aspera al senor; sta fuerte; y él fortificara tu coraçon; y aspera al senor (Sal 27,14) ॥ Ved que el ojo del Señor mira a los que lo temen, a los que asperan su misericordia (Sal 33,18) || Nuestra anima aspera al senor; nuestro socorro y nuestro escudo es él (Sal 33,20) \| Sea, senor, tu misericordia sobre nosotros, segun que te auemos asperado (Sal 33,22) || Asperando aspere al senor (Sal 40,2) || El denuesto ha quebrantado a my coraçon y estoy debilitado; he asperado consuelo y no lo ay $($ Sal 69,20$)$ Los ojos de todos asperaran a ti; y tu das a ellos su manjar a su tiempo (Sal 145,15).

c. Mejor es esperar en el Señor que confiar en hombre; Mejor es esperar en el Señor que confiar en príncipes (Sal 118,8-9).

A la luz de este uso enfrentado podemos revisar los ejemplos de (40) como contravenciones a este empleo: en (40a) porque asperar en la palabra parece sintagma de sentido metafórico ('tener esperanza en') que se vincula, además, con la preposición en, por lo que cabría entender que en tal caso se han cruzado los casos de asperar (al señor) y esperar (en su palabra); por último, a la luz del uso preconizado en el Diálogo y asegurado por 40b cabe corregir la acción de Ricart como editor (40c) al restituir una preposición asperaré (en) tu nombre, que en la edición de Boehmer ${ }^{50}$, en cambio, no se practica.

(40) a. Esperado he al Señor, esperado ha my ánima, y en su palabra he asperado (Sal 130,5).

b. Desfallecido ha my anima en la sperança de tu salud; en tu palabra he asperado (Sal 119,81).

c. Confessarete perpetuamente porque heziste esto, y asperare [en] tu nombre, porque bueno es delante de tus misericordiosos (Sal 52,11)

En las variantes vocálicas o consonánticas de partículas discursivas y formas verbales hay notable coincidencia con lo preconizado explícitamente por Valdés en el Diálogo. No aparecen jamás ansí ni dende ni entonces y sí assí, desde y estonces (41). Lo mismo puede decirse para ciertas variantes consonánticas: en el Salterio no hay resgate sino rescate en usos verbales y nominales (42):

50 Boenmer, El Salterio traduzido, pág. 56. 
(41) a. M.: Adonde vos escrivía estonces, y assí, y desde, otros escriven entonces, ansi y dende, mudando la $s$ en $n$. ¿Tenéis alguna razón que os mueva a escrivir $s$ antes que $n$ ?

$\mathrm{V}$. La principal razón que tengo es el uso de los que bien escriven [...] en los vocablos que avéis dicho sta mejor la $s$ que la $n$, la qual creo se ha metido allí por inadvertencia ( $D L$, pág. 179)

b. estonces (Sal 2,5, 22,31, 40,8 y 61,19).

c. desde (Sal 3,4 y 14,2).

d. assi (Sal 1,4).

(42) a. M.: dezidme ahora si resgate y rescate es todo uno.

V.: Todo, y el propio es rescate ( $D L$, pág. 173).

b. rescata (Sal 25,22); rescátame (Sal 26,11); rescatásteme (Sal $31,5)$.

\subsection{Usos gramaticales cotejados}

La morfología derivativa coincide con los gustos valdesianos en la preferencia por mostrar y prestar ante variantes como demostrar o emprestar $(43,44)$. En la morfofonética verbal también hay una notable coincidencia entre lo preconizado por Valdés en el Diálogo y lo usado en la copia del Salterio. En ella, no hallamos muestras de radical en - $a$ para el perfecto de traer (45a) y es constante el uso de truxo, truxiste; tampoco hay rastro de formas con epéntesis para el futuro sintético de salir, repudiadas por Valdés igualmente en el Diálogo (46a):

(43) a. M. ¿Y quál tenéis por mejor, dezir mostrar o demostrar?

$\mathrm{V}$. Tengo por grossería aquel de demasiado, y por esso digo mostrar (DL, pág. 191).

b. mostraste (Sal 60,3); mostrar (Sal 21,9).

(44) a. M. Unas vezes siento dezir prestar, y otras enprestar; ¿quál tenéis por mejor?

V. Tengo por grossero el enprestar (DL, pág. 191).

b. presta (Sal 37,26 y 112,5); prestado (Sal 37,21).

(45) a. M.: [...] veo y siento que muchos cortesanos, cavalleros y señores dizen y escriven traxo.

Por la mesma razón que ellos escriven su traxo escrivo yo mi truxo; vosotros tomad el que quisiéredes ( $D L$, pág. 158). 
b. truxiste (Sal 77: 20); truxo (Sal 78,26 y 136,16); trúxolos (Sal 78,52 y 53).

(46) a. M.: ¿por qué scrivís salliré por saldré que scriven otros?

V.: Porque viene de sallir (DL, pág. 161).

b. salirás (Sal 60,10 y 68,23).

En lo que se refiere al reparto de adonde (tras consonante o pausa) $\mathrm{y}$ donde (tras vocal), los resultados observados son inestables (se respeta en $47 \mathrm{~b}$ pero no en $47 \mathrm{c}$ ), como cabe esperar de una distinción de demasiada sutileza para un manuscrito copiado; la misma situación se observa en el propio manuscrito del Diálogo de la lengua que no respeta esa recomendación ${ }^{51}$. Respecto a la distribución de posesivo antepuesto o pospuesto según el uso nominativo o vocativo del sustantivo señor, la recomendación del DL (48a) se respeta en general bastante (48b) con solo alguna contravención (48c):

(47) a. M. [...] he notado en vuestras cartas que en algunos vocablos unas vezes ponéis $a$ al principio, y otras no, diziendo cevadado y acevadado, sentado y asentado, donde y adonde, llegado y allegado, ruga y arruga, vezado y avezado, etcétera.

$\mathrm{V}$. Si avéis bien mirado en ello, hallaréis que pongo $a$ cuando el vocablo que precede acaba en consonante, y no la pongo quando acaba en vocal ( $D L$, pág. 157).

b. Ally temieron temor adonde no auia temor (Sal 53,5).

c. Bienauenturado el pueblo adonde conocerán la jubilación (Sal 89,15); Ally adonde anidarán páxaros, la cigüeña terná (Sal 105,17).

(48) a. quiero que sepáis que la lengua castellana siempre quiere el pronombre delante del nombre, si no es quando el nombre sta en vocativo, que estonces el pronombre sigue al nombre. De manera que, hablando bien, avéis de dezir mi señor y mi señora, mi padre y mi madre, quando están en nominativo, pero si estos nombres están en vocativo avéis de dezir señor mío y señora mía, padre mío y madre mía. Mas quiero sepáis que, si estando estos nombres en vocativo, ponéis el pronombre antes que el nombre, hazéis que la cortesía sea mucho menor, y de aquí es que ay muy gran diferencia de scrivir a una dama «Señora mía» o «Mi señora», porque, luego que de industria os apartáis del propio stilo de la lengua en que habláis

51 Kormi AnIPA, The Grammatical Thought and Linguistic Behaviour of Juan de Valdés (Múnich: Lincom, 2007) pág. 160. 
o escrivís, mostráis tener por inferior a la persona con quien habláis, o a quien escrivís ( $D L$, pág. 153).

b. Despierta y vela á my juizio; Dios mío y señor mío, á my lite (Sal 35,23); Porque tú eres my esperança; Señor, Señor mío confiança mía, desde my niñez (Sal 81,5); Y tú, señor mío, haz por my por tu nombre (Sal 109,21); Señor, señor mío, fuerça de mi salud, cubriste a my cabeça en el dia de arma (Sal 140,7); Porque a ti, señor, señor mío, miran mis ojos (Sal 141,8).

c. - Y á my, el llegarme a Dios me es bueno; he puesto en el Señor, señor mío, my confiança (Sal 73,28).

\subsection{Usos léxicos cotejados}

En las preferencias léxicas hay algunos datos de interés. Tenemos, en primer lugar, las palabras que explícitamente rechaza Valdés en favor de otras en el Diálogo. En numerosos casos, el Salterio valdesiano consuena con lo dicho allí y hay coherencia entre lo escrito en la traducción y lo prescrito en el Diálogo: planto suplanta a llanto y a lloro (49), se usa segur y no hacha $(50)^{52}$, aina falta y es frecuente presto $(51)^{53}$, no aparece pedir y sí en cambio demandar $(52)^{54}$, mientras borra a entre tanto (53) y el pronombre ninguno se usa en lugar de nadie (54):

(49) a. M.: ¿quál os contenta más, llanto o planto?

V.: Por mejor tengo dezir planto (DL, pág. 177).

52 Recordemos (DCECH, s. v. hacha II) que segur era la denominación vernácula para este instrumento, especializada la voz hacha en un principio en el sentido de 'hacha de guerra'. Al empezar a usarse hacha con el sentido de 'instrumento para cortar leña', segur comenzó a decaer ya en el siglo xv.

${ }^{53}$ La preferencia se constata en otras obras valdesianas: a los ocho ejemplos de presto que se localizan en el Salterio podemos sumar los cuatro del Diálogo de doctrina cristiana, los propios nueve del Diálogo de la lengua o los dos que encuentro en los comentarios paulinos.

${ }^{54}$ Los seis casos de demandar en el Salterio consuenan con lo hallado en el Diálogo de doctrina cristiana (cinco casos de demandar). Distinta preferencia idiolectal tiene el uso nominal, en que demanda está en minoría con respecto a petición, mas abundante en el Salterio y en el Diálogo de doctrina cristiana. 
V.: Antes digo planto que lloro (DL, pág. 230).

b. he mezclado mi beuer con planto (Sal 102,9); Tornásteme my planto en bayle (Sal 30,11).

(50) a. V.: Antes [digo] segur que hacha (DL, pág. 218).

b. Parece como el poner segures en lo alto del áruol espesso (Sal 74,5).

(51) a. Antes [digo] presto que aína (DL, pág. 230).

b. [P]orque se encenderá presto su ira ( $\mathrm{Sal} 2,2)$; porque como yerua, presto serán segados (Sal 37,2); más presto que vuestras ollas sienten la espina (Sal 58,9); de presto los asaetearán y no temerán (Sal 64,4).

(52) a. Antes [digo] demandar que pedir ( $D L$, pág. 230).

b. Demándame y yo te daré gentes (Sal 2,8); Demandote vida, y dístele longueza (Sal 21,4); Una gracia he demandado al Señor (Sal 27,4).

(53) a. Mientras por entre tanto querrían algunos desterrar, pero, porque me parece no tienen razón, si pudiesse lo defendería ( $D L$, pág. 204).

b. cantaré a my Dios mientras seré (Sal 105,33) \| guardaré my boca con boçal mientras stá el impío delante de my (Sal 39,1).

(54) a. Mejor vocablo es ninguno que nadie, aunque a nadie le da reputación aquel galanísimo dicho «Quien a sí vence a nadie teme» $(D L$, pág. 204).

b. contigo no he querido á ninguno en la tierra (Sal 73,25).

Por otra parte, el Salterio verifica la introducción de neologismos o palabras latinas propuesta por Valdés en el Diálogo, como las voces jubilar ${ }^{55}$ o insolencia:

(55) a. Querría más introduzir paréntesis, insolencia, jubilar, temeridad, professión (DL, pág. 220).

b. jubilad al Dios de Jacob (Sal 81,1); jubilación (Sal 89,15), jubilemos (Sal 95,1).

b'. También de las insolencias refrena á tu sieruo (Sal 19,13); insolencias de varón (Sal 31,20); a que obra insolencia (Sal 31,23); insolentes se an leuantado (Sal 86,14).

${ }^{55} \mathrm{La}$ voz se da en los primeros textos castellanos con el sentido de 'alcanzar la jubilación' y había aparecido ya en los vocabularios nebrisenses (jubilado, suelto de trabajo: emeritus; jubilar, suelto ser assi). 
En cambio, también en el Salterio vemos contradichas ciertas recomendaciones o predilecciones que aparecen en el Diálogo de la lengua y que conciernen a usos léxicos concretos. El Salterio contiene ocurrencias de henchir, fiuzia, quemar, odre, perro y deshonra (citas en b), voces que Valdés explícitamente rechaza en el Diálogo (citas en a) en favor de llenar, confianza, abrasar, cuero, can y denostar que aparecen ( $c$ en todos los casos) o no conviviendo con las anteriores en el Salterio.

(56) a. Henchir parece feo y grossero vocablo, y algunas vezes forçosamente lo uso por no tener otro que sinifique lo que él porque llenar no quadra bien en todas partes ( $D L$, pág. 200).

b. SeÑor Dios tuyo, que te hize subir e la tierra de Egitto; abre tu boca y henchiréla (Sal 81,11);

(57) a. por mejor tengo confiança que fiuzia ni huzia (DL, pág. 199).

b. Afligido y desafiuzado soy yo (Sal 88,15$)$.

c. me hazes morar confiado (Sal 4,8); my carne morará confiada (Sal $16,9)$ etc.

(58) a. antes [digo] abrasar que quemar ( $D L$, pág. 230).

b. quema carros con fuego (Sal 46,9); an quemado todas las sinagogas de Dios en la tierra (Sal 79,8); como fuego que quema bosque (Sal 83,14); fuego caminará en su presencia, y quemará aderredor á sus aduersarios (Sal 97,3); fuego que quema (Sal 105,4); mis huessos, como el hogar están quemados (Sal 102,3).

c. La llama abrasó a los impíos (Sal 106,18).

(59) a. Odre y odrero solían dezir por lo que agora dezimos cuero y botero; a mí, aunque soy mal moxón, bien me contenta el odre, porque no es equívoco como el cuero, pero no lo osaría usar, y odrero sí, siquiera por amor de la profecía de Toledo ( $D L$, pág. 204).

b. pon en tu odre mi lágrima (Sal 66,8); aunque he estado como odre al humo (Sal 119,83).

(60) a. Antes [digo] can que perro ( $D L$, pág. 230).

b. porque perros me tienen cercado (Sal 22,17); Libra my ánima de cuchillo; de mano de perro la que me es vnica (Sal 22,21); retornan a la tarde; regañan como perro (Sal 59,6).

(61) a. Por deshonrar diré denostar (DL, pág. 230).

b. Cada dia my deshonrra stá delante de my, y la uerguença de my cara ha cubierto (Sal 44,15). 
c. Mirarán hazia él y serán alumbrados; y sus caras no serán denostadas (Sal 34,5); Queden confussos y avergonçados los que buscan a my ánima; tornen atrás y sean denostados los que piensan my mal (Sal 35,4).

Si consideramos con detalle alguno de los pares vemos que las opciones léxicas valdesianas en el Salterio y el Diálogo consuenan de forma irregular con las de otras de sus obras. Así, para (61, denostar, preferido a deshonrar) vemos que en el Salterio hay un solo caso de deshonrar, que convive con catorce de denostar; pues bien, en el Diálogo de doctrina cristiana figura otro ejemplo de denostar pero en el Comentario a las cartas paulinas hay cinco casos de denostar frente a una cifra superior en el uso de deshonrar. Para el caso del par perro / can (60), el Diálogo de la lengua ofrece la voz perro solo dentro de refranes, pero fuera de ellos Valdés la usa un par de veces en el Diálogo de doctrina cristiana, además de las cinco ocurrencias que presenta en la traducción de los Salmos. Por otra parte, la tradición de versiones bíblicas muestra que las variaciones en estas formas son constantes ( $c f$. Corpus Biblia Medieval) ${ }^{56}$.

En resumen, el cotejo invita a considerar las preferencias léxicas valdesianas como formulaciones no excluyentes ${ }^{57}$, que sí reduce en uso la palabra preterida pero que no la destierra por completo del idiolecto valdesiano; de hecho, el propio autor no siempre formula sus preferencias léxicas en sentido excluyente. Por ejemplo, si Valdés dice preferir falta y faltar a falla y a fallecer, en la traducción del Salterio deja varios testimonios de fallecer en el sentido de 'fenecer, morir':

56 Andrés Enrique-Arias, (dir.), y Fco. Javier Pueyo Mena, Biblia Medieval (accesible en línea en $<$ http://corpus.bibliamedieval.es> [última consulta: 30/01/2021].

${ }^{57}$ No incluyo en este grupo de prescripciones del Diálogo contravenidas en el Salterio la recomendación sobre purgar («De la mesma manera, quiriendo dezir "mañana me purgo" digo "mañana tomo medicina"», $D L$, pág. 231) que no es burlada en el ejemplo salmorial «Palabras o cosas de iniquidades preualecieron sobre my; nuestras rebeliones tú las purgarás» (Sal 65,3), ya que Valdés se refiere a la acepción de purgar como 'Limpiar y purificar alguna cosa, quitándole todo quanto la puede hacer imperfecta, ó no le conviene' y no a la del texto bíblico, 'En sentido morál vale purificar y acrisolar Dios las almas virtuosas, por medio de los trabajos y aflicciones' (apud Autoridades 1737 , s. v. purgar). 
(62) a. Mejor me parece dezir falta que falla, y faltar que fallecer, aunque el refrán diga: «Amigos y mulas fallecen a las duras» (DL, pág. 199).

b. hijos estraños fallezen y temen en sus encerramientos (Sal 18,45) || Porque los impíos perecerán, y los enemigos del Señor como lo preciado de los corderos: fallecen, en humo fallecen (Sal 37,20) \| fallecido an como humo mis días (Sal 102,3).

Este es un empleo interesante, por cuanto fallecer, equivalente durante toda la Edad Media a fallir, se fue restringiendo desde el siglo XVI al valor que le damos hoy, un eufemismo para 'morir y, como vemos, en el Salterio solo se documenta esta voz con ese sentido eufemístico ${ }^{58}$.

\section{PARA terminar}

Parece probada la fuerte conexión existente entre lo que se dice en el Diálogo y lo que se usa en el Salterio. Un escrupuloso nivel de respeto en cuestiones de grafía y fonética permite considerar la copia vienesa conservada del Salterio como un apógrafo surgido del entorno valdesiano o, al menos, una copia que tiene como antígrafo un manuscrito muy cercano a la mano valdesiana. En ello resulta equiparable al códice óptimo conservado del Diálogo, ya que ambos muestran bastante apego a las decisiones valdesianas en cuestiones que están fuertemente sometidas a la voluntaria intervención de un copista poco aleccionado sobre un usus scribendi que ha de respetar. Con todo, hay, como hemos visto, contravenciones a lo léxico que deben ser entendidas como preferencias enunciadas en el Diálogo que no estuvieron tan presentes por Valdés antes de escribirlo ni resultaban tan hirientes para él.

Como ya advirtió Barbolani ${ }^{59}$, separar en dos la obra valdesiana entre escritura profana (el Diálogo de la lengua) y religiosa (el resto)

58 También se documenta desfallecer en varios casos, entre otros: «por la contienda de tu mano yo estoy desfallecido» (Sal 39,10); «an desfallecido mis ojos del asperar á my Dios» (Sal 69,3); «desfallecen my carne y my coraçón» (Sal 73,26).

59 Vid. Cristina Barbolani, «Los diálogos de Juan de Valdés ireflexión o improvisación?», en Doce consideraciones sobre el mundo hispano-italiano en tiempos de Alfonso y Juan de Valdés (Bolonia, abril de 1976), eds. y coords. F. Ramos Ortega et alii (Roma: Publicaciones del Instituto Español de Lengua y Literatura de Roma, 1975) págs. 135-154: 138. 
provoca una separación de la bibliografía y de las descripciones que se hacen de Valdés en las historias de la literatura. Pero una cabal aproximación a la obra valdesiana, al menos, una aproximación al Diálogo de la lengua que quiera entender por qué se escribe esta obra (pintada como entretenimiento honesto por su autor en una de sus páginas) tiene que partir de la biografía espiritual y material del autor. Sobre su obra el foco se ha puesto tanto en el Diálogo de la lengua que se ha colegido erróneamente que es esa la obra principal de un autor que en realidad se pone a escribir, hay que recordarlo, para explicar la doctrina cristiana, para iluminarla con nuevas traducciones bíblicas y con nuevos libros de aprendizaje como catecismos de diferente tipo.

En su comentario al Evangelio de San Mateo $(20,10)$ Valdés advertía: «Tengo por experiencia que nunca mejor hablé en mi vida que cuando he hablado sin haberme puesto a pensar lo que había de hablar; lo mismo digo del escribir». Este innegable preludio del escribo como hablo, la frase más citada del Diálogo de la lengua, anuncia la primera conclusión que es para mí relevante de un acercamiento desde la historia de la lengua a la obra religiosa valdesiana: el hecho de que su producción letrada teológica alberga también de forma espigada una interesante información sobre preferencias lingüísticas, que tienen su pertinencia en el contexto de la escritura de un traductor que habla sobre hechos de contrastividad lingüística.

Es dentro de una escritura que es por completo de naturaleza religiosa donde hay que enclavar el Diálogo de la lengua, solo entendido de forma correcta si tenemos en cuenta dos factores: escribe alguien que ha dedicado buena parte de su tarea intelectual a interpretar traduciendo desde libros y escribe alguien que redacta el Diálogo en el espacio comunicativo napolitano del Quinientos cuando también está traduciendo (entre castellano e italiano) en la comunicación cotidiana. La reflexión metalingüística valdesiana es deriva de una producción intelectual religiosa en la que ha traducido desde el griego y desde el hebreo. El Diálogo de la lengua solo se explica dentro una escritura consagrada a la hermenéutica bíblica.

Recibido: $17 / 06 / 2020$

Aceptado: 19/04/2021 